Article

\title{
An Integrated Diagnostic Framework to Manage Organization Sustainable Growth: An Empirical Case
}

\author{
Jingxiao Zhang ${ }^{1, *}$, Klaus Schmidt ${ }^{2}$ and $\mathrm{Hui} \mathrm{Li}^{1, *}$ \\ 1 School of Civil Engineering, Chang'an University, NO.161, Chang'an Road, Xi'an 710061, China \\ 2 Technology Department, Illinois State University, Normal, IL 61790, USA; kschmid@ilstu.edu \\ * Correspondence: zhangjingxiao@chd.edu.cn (J.Z.); lihui9922@chd.edu.cn (H.L.); \\ Tel.: +86-159-2973-9877 (J.Z.); +86-159-9138-5822 (H.L.)
}

Academic Editor: Giuseppe Ioppolo

Received: 5 January 2016; Accepted: 16 March 2016; Published: 24 March 2016

\begin{abstract}
This research aims to develop a quantitative diagnostic framework by combining the Weisbord six-box model with the growth management model to focus on an organization's internally driven sustainable management system. The research adopted an instrument developed by Preziosi and an extended Weisbord six-box model. The research employed a survey to collect 180 samples in a Chinese petrol company and applied the comparative method: (a) the average score method; and (b) the entropy method to confirm the growth level of the company. The survey also attempted to identify corresponding top growth influence factors using the obstacle degree formula. The results showed that the integrated diagnostic framework worked well to diagnose a regional but large Chinese petroleum company. In other words, the research successfully quantified the growth position and top influence factors and helped put forward specific suggestions to drive the organization of sustainable development. The method confirmed this organization during the fourth phase of five phases. In addition, top influence factors hindering the internal growth were (a) the lack of task engagement with energy and time; (b) the lack of personal work units; and (c) a poor division of labor for reaching sustainable growth rates. The research provides a generic theoretical framework support to incorporate growth management models into an organizational diagnosis to obtain sustainable growth. It further highlights and practices guidelines in examining actual growth management levels in companies and discusses top influence factors to design efficient management systems to pursue organizational growth in a multitude of industrial contexts.
\end{abstract}

Keywords: integrated diagnostic framework; organizational diagnosis; change management for sustainability; organizational growth management; entropy method

\section{Introduction}

Organizational diagnosis has been referred to as a management tool to promote organization development and change for sustainability [1-3]. Some practitioners have believed that the bulk of organizational diagnosis for internal growth management has little or no new assessment technology [4-8].

Organizational change for internal management growth is a process of working with people and resources within purpose, structure, rewards, support mechanism, and leadership to complete the organizational change for sustainability [9-12]. In this context, change management for sustainability is increasingly recognized as a key determinant of success or failure, and the success of international business in multinational companies depends most significantly on the quality of internal management systems [13-16]. Additionally, efficient change management for sustainability is crucial in achieving corporate (national or international/multinational) goals such as higher value, comprehensiveness, corporate governance, and the like $[17,18]$. Efficient change management for sustainability can be 
achieved by resolving companies' internal problems with different stakeholders $[19,20]$. In large companies, organizational development problems may exist within the organizational purpose, structure, vision, and leadership as well as employee attitude toward change [20-22].

There are numerous descriptions of organizational diagnostic models in the literature [23-25], such as force field analysis, Leavitt's model, Likert system analysis, open systems theory, the Weisbord six-box model, McKinsey 7S framework, and the Burke-Litwin model. The Weisbord model focused on internal issues within an organization primarily by posing "diagnostic questions" which identify the "what is" and "what should be" [26]. At the same time, there are sustainable models with the purpose to develop process management for organizational change $[27,28]$, such as the Process Model for Embracing Sustainability [28], and the growth management model (GMM) [27]. The GMM focused on the internal factors to initiate the change as a basis to pursue an organization's overall performance and value in the sustainable process management. However, little research exists about incorporating the organizational diagnosis model into the sustainable management model to fit an organization's attempt to incorporate sustainable change management systems and to pay more attention on the internal and evolutionary growth analyses. Therefore, the researchers identified the original needs and developed a practical guide to designing a diagnosis framework to manage an organization's sustainable growth potential by diagnosing the internal influencing factors to help the organization grow in a sustainable fashion. With this framework, we will learn more than we now know about how to (a) quantitatively identify the current growth levels, which is the prerequisite for an organization to know what the future direction is and how long the path is for it to pursue the best growth practice; (b) quantitatively analyze the major problem areas to deal with embedded influence factors at the current level to change more effectively.

The research for this study was conducted in PetroChina South Sulige Operating Company (PSSOC), which is a regional large company of PetroChina's Changqing Oilfield Company. The China Petro industry is facing the challenge of transitional development such as organizational change, business restructure, and product innovation. This study emphasized the need for internal diagnosis toward the changing practices for organizational growth to be a more widely accepted practice in the future.

The aim of this study is to quantitatively evaluate the level of organizational internal change management for sustainable growth and analyze the corresponding influence factors. In order to fulfill this research purpose, this paper built an integrated framework drawing on both the Weisbord six-box model of organizational change management and the GMM of organizational sustainable management to confirm the level of organizational internal evolutionary growth with two comparative methods. The researchers used the major impact index formula [29-31] to generate the influence factors at the organizational current level to propose the targeted suggestion to promote the transition by dealing with the focused internal issues in institutional contexts.

This research pointed toward a range of powerful quantitative approaches both for establishing organizational internal evolutionary growth levels and for targeting the corresponding problem areas and influence factors in the field of organizational change for sustainability. This framework and quantitative approach, which were tested at a main branch of a large petro company, should not only be a springboard for future research but also a practical guide for other companies matching the generic framework of organizational internal diagnosis for management growth.

The rest of the paper is structured as follows. Section 2 shows related literature such as change management and sustainable management in order to build the integrated framework. Section 3 provides the methodology. Section 4 applies the developed model to implement the procedure and measurement to analyze the empirical case. Section 5 presents the conclusions, summarizes the results, and highlights the implications for similar scenarios and other industries. 


\section{Literature Review}

\subsection{Change Management}

\subsubsection{Brief Theory Review}

Change management is not only a challenging and continuous process to organizational success and survival, but also a critical issue in the field of organization development. Changes can lead to improved organizational performance and enhance the chances of organizational survival to sustain the business growth [32-34].

Change cannot be successfully implemented if members in the organization do not accept the change and do not change themselves [35]. Change may be resisted even though it is necessary, and cannot occur unless employees are motivated and ready for it $[17,36]$. Therefore, change management mainly depends on its organizational structure and willingness to respond to the surroundings in which it operates, which may transform the present organizational structure into a new way of managing the organization.

In this study, change management is defined as the process an organization applies to design, implement, and evaluate appropriate internal initiatives to deal with sustainable development demands by organizational adjustments [19,32,33].

For management adaptation, organizational change for sustainable development involves moving an organization from its present position to its desired position through a transition period [37,38]. It is essential for leaders and change agents to understand and address the impact factors, such as version, attitudes, and purpose of the company's organizational development. It is important to assess how these determinants affect individuals' behaviors, attitudes, leadership, and responses toward organizational change, and how possible resistance issues associated with organizational change may hinder organizational sustainable development $[39,40]$.

\subsubsection{The Weisbord Six-Box Model}

There are many factors that can drive organizational change. For example, Cook et al. (2004) highlighted several factors which are critical to successful change management including leadership and shared vision, strategic management, responsibility, purpose, teamwork and collaboration, open communication, respect, support of others, effective problem solving, active participation, and information flow [36]. Change models need to be described in detail in order to reveal why change occurs (driving forces of change), how change will occur (stages, scale, timing and process), and what will occur (content of change, outcome and why to measure it) $[18,33,41]$. In order to conceptualize the need for change, as stated above, the Weisbord six-box model, as one of numerous outstanding models [23-25] to highlight and focus on the organization internal management, provided a good guideline for determining what internal factors need to be acquired by individuals or organizations in order to facilitate the adaptation of organizational change management practices at the operational level. Furthermore, the Weisbord six-box model offered utilization to determine what motivational factors influence the adaptation of management practices, and it assisted the analysts in addressing different groups of frequently occurring organizational problems [26].

Weisbord proposed a diagnostic instrument that included 30 items, which were used to quantify the six variables of the model. For example, Weisbord suggested that organizational diagnosis consultants determined whether organizational members agreed with and supported the organization's mission and goals within the purposes box. On the basis of the Weisbord six-box model, Preziosi's organizational diagnostic questionnaire [42] included, in addition to Weisbord's 30 original items, five more to reflect an additional factor, namely, "the attitudes toward change" of members of the organization.

Preziosi's instrument extended the Weisbord six-box model and provided a diagnostic tool that identifies six areas to examine when organizational change is required [43-46]. For example, Lok and 
Crawford (2000) applied the six-box model in two leading companies in Australia, which indicated that the only significant variables were purpose and attitudes toward change [43]. Roxana Stegerean (2010) started working on using the six-box model to make organizational diagnoses in the largest cosmetics company in Romania, which was confronted with a change in the management team in 2009 [39]. Rahim and Siadat (2011) utilized the six-box model to diagnose a university, which has a dynamic interaction with the environment [47]. Marketa (2012) applied the six-box model to a functional campus community environment and found that the university has different perspectives and many diverse groups that have particular job descriptions and responsibilities [48].

To summarize, the Weisbord six-box model is intended to assist individuals in understanding internal issues within an organization primarily by performing more effectively, by specifying problem areas, and then by making suggestions and initiating procedures for improvements. As mentioned above, for organizational development, management should know which phase the organization has arrived at, and should then proceed to focus on internal issues. Internal issues are the focus of the Weisbord six-box model. Therefore, the Weisbord six-box model helps to determine what motivational factors influence the adaptation of organizational growth management practices. In the following, we incorporated the growth management model of sustainable management areas into the Weisbord six-box model to form a contingency model, which services the growth position on basis of an organizational diagnosis. Additionally, the Weisbord six-box model has not been used in the Chinese petroleum industry, and this research supplements a new application for the prevalency of the Weisbord organizational model in the petroleum industry in developing countries.

\subsection{Sustainable Management}

\subsubsection{Brief Theory Review}

Organizational sustainable management takes the concepts from sustainability and synthesizes those with the concepts of organizational management, which is central to realizing the corporate value, corporate evolutionary growth, and corporate internal adjustment. Sustainable management is increasingly recognized as a central determinant in embracing sustainability with a clear process and steps, arguing that the success of multinational companies depended most significantly on the process quality of management systems $[11,49,50]$. Embracing sustainability implied changing deeply embedded customs into management systems that are sustainable and environmentally friendly and that ensure the growth requirements of the organization $[49,51,52]$.

One of the reasons why building truly embedded sustainable organizations is difficult is that it often requires a significant shift in the identity of the firm, as well as a shift in the core structure and resource support. Furthermore, researchers agree that large-scale organizational change of any magnitude was always hard, and existing cognitive frameworks shaped the perceptions of an organization's employees so that possible threats are often denied or discounted [53,54]. One appropriate way to achieve sustainable management includes resolving embedded agency problems among different stakeholders. Another way may include making adopting new configurations to alternate and replenish the complementarities between existing organizational practices. A third way may be dealing with agency dilemmas associated with inertia both within the firm and within its institutional context [11,50,55-57]. In large corporations, organizational development problems may exist between managers, employees, staff, and other stakeholders who had different viewpoints of organizational purpose, vision, resource support, and human relationships [58-61]. At the same time, large-scale organizational change in response to the challenge of environmental sustainability is not only necessary but also eminently possible, which laid out a road map that we hope will support organizational leaders to grapple with the coming transition $[50,57,62,63]$. Thus, the inner organization of sustainability for change is integrated with the organization's business strategy so that value generated through sustainability initiatives has a direct impact on the organization's overall performance $[64,65]$. These organizations see sustainability as a generative opportunity that has the potential to alter the organization's basis for competing and 
generating value in its internal-driven change [50,57,62,63]. Additionally, there is compelling evidence that as corporations wrestle with the challenge of building a sustainable organization should clearly know at what level of transformation they are and then focus on the core issues by proceeding with the appropriate steps. Therefore, there is a need to build a thorough understanding of the sustainable processes to implement change throughout the firm and to quantitatively analyze the phase of sustainable management of large companies mainly by the embedded influence factors, which cause differences in the interests of different stakeholders in the organization.

There are several sustainable models about process management for organizational change $[27,28]$. For example, the Process Model for Embracing Sustainability and the GMM. Silvestri and Gulati proposed a Process Model for Embracing Sustainability and suggested that "bringing sustainability to the core requires moving through four stages-imagining, experimenting, planning, and consolidating - and illustrate the model through a rich description of the successful transformation of the Ford motor company" [28]. Moreover, this process model focused on "sustainability as a way of managing their relationships with external constituencies, rather than a fundamental component of the member's personal and collective commitment to what the organization is and what it strives to become" [28].

Like Charles McIntyre's statement [27], the GMM framework roots itself in basic management theory which is applicable to any business or organization. The GMM model is generic in nature and refers to any industry. It focuses on the internal and evolutionary growth which occurs within any industry, which varies from agriculture to manufacturing industry. Being aware of this, in 2015, McIntyre provided a structured and sequential approach to improve managerial proficiency with the ultimate goal of enhancing outcomes by means of models that are similar to the Industry Advisory Board (IAB) GMM [27]. As a managerial instrument, the GMM model is designed to enhance Managerial Proficiency of an organization, an attempt to improve organizational outcomes.

\subsubsection{The GMM Model}

According to the IAB GMM, and with regard to Preziosi's instrument that extended the Weisbord six-box model, organizational Managerial Proficiency consists of seven subsystems: Organizational Purpose systems, Structure systems, Relationships systems, Helpful Mechanisms systems, Rewards systems, Leadership systems, Environmental systems and Attitudes Toward Change systems. They are all primary components of Managerial Proficiency of organizational change toward sustainable development. In addition, organizational outcomes are defined as the number and quality of best practices conducted by an organization within these seven proficiency systems.

An increase in IAB Outcomes or quality of IAB Outcomes necessitates an increase in organizational Managerial Proficiency. Transition periods may result in interpersonal conflicts because of new expectations and higher anticipated efficiencies. During the transition periods, IAB members are typically being asked to step out of their personal "comfort zones" and meet new challenges.

In this process, GMM provides a fundamental theory to understand the significance of effective Managerial Proficiency. In the organizational GMM framework, the vertical axis represents Managerial Proficiency and the horizontal axis relates to an organization's Outcomes. The relation between Managerial Proficiency and organizational Outcomes is expressed by a series of management plateau levels (such as IAB level I) which are linked by several lines called transition periods. These four management plateaus represent the IAB Outcomes which can be achieved at each level of Managerial Proficiency. These plateaus are "stability zones" where the IAB Outcomes match the organization Managerial Proficiency exactly.

Thus, this research followed the thought of GMM replenishing the corresponding Preziosi's instrument-extended Weisbord six-box organization model to form a new integrated diagnostic model for an organizational internal and evolutionary growth in the stance of organizational change management, illustrated in Figure 1. 
As the integrated model in Figure 1, the vertical axis represents Managerial Proficiency and the horizontal axis relates to Scores. Scores are marked by grades, which are calculated in the samples. The relationship between Managerial Proficiency and Preziosi's Scores is represented by a series of management plateau levels (varying from level I to level IV, and more levels if possible) linked by transition periods. These plateaus mean that a stable level of Managerial Proficiency has been reached while transition periods represent the process where actions are taken in order to achieve the next level.

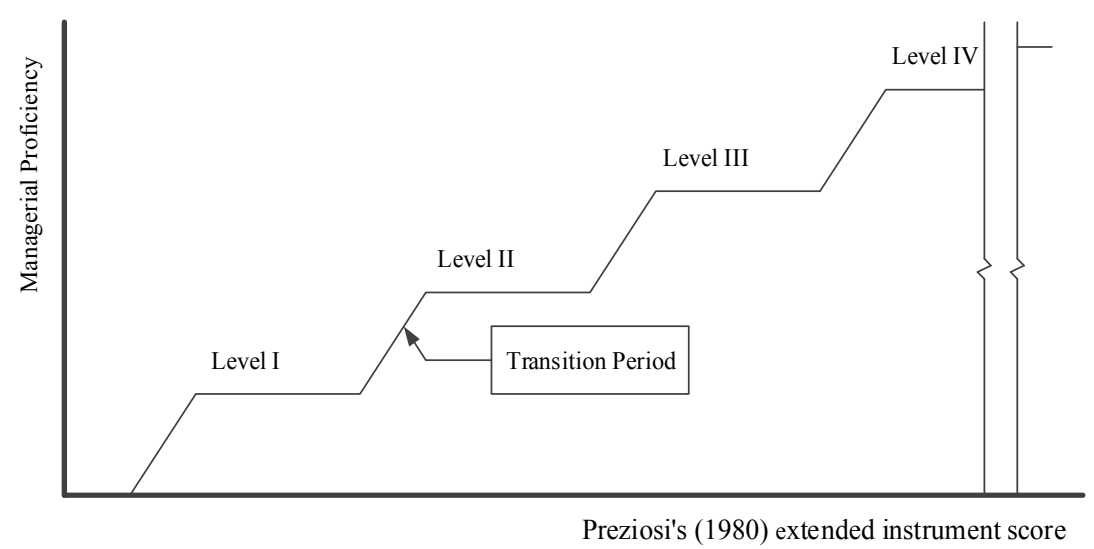

Figure 1. Incorporating GMM into organizational diagnose.

\subsection{Analysis Level}

GMM provided an instrument to analyze the stage at which companies or organizations operate with respect to change management. In the position of the integrated model of the Weisbord six-box model and GMM (WSBGMM), with the application of two quantitative compared methods, we can understand the organization's evolutionary stage by using an internal organizational diagnosis to make targeted efforts to achieve sustainable growth [42]. The theoretical framework of this research is shown in Figure 2, and the corresponding research steps are illustrated in Figure 3.

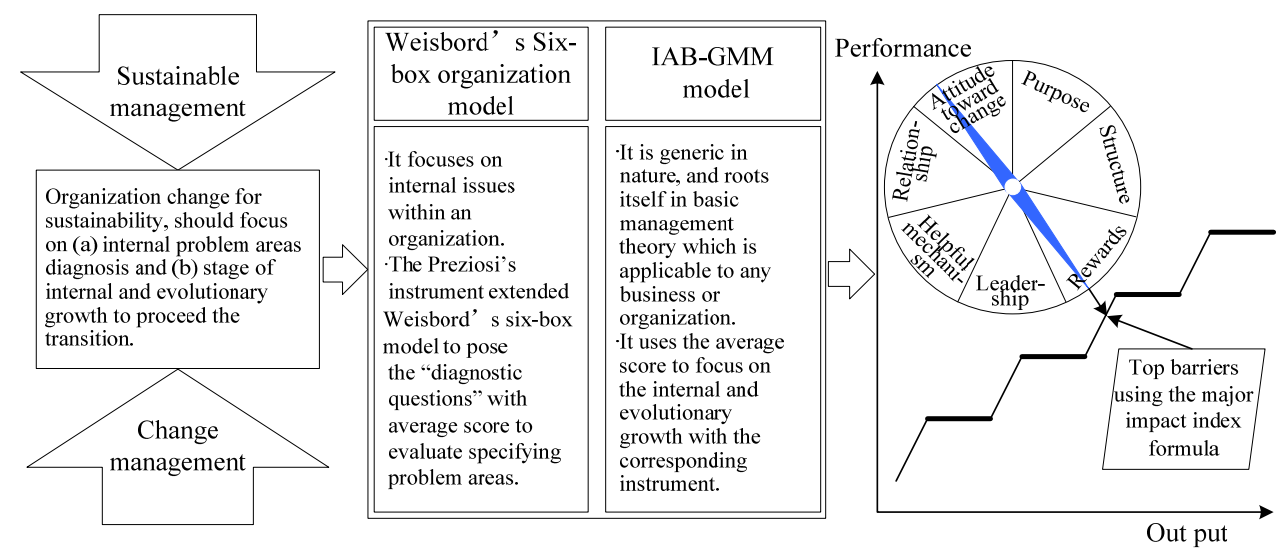

Figure 2. Theoretical framework with focus on explaining the integration between the Weisbord six-box model and the GMM (WSBGMM).

As shown in Figure 3, this research applied entropy weighted sums to confirm the compared GMM results and proposes another alternative method to enrich the quantitative analysis of the GMM levels $[66,67]$. 


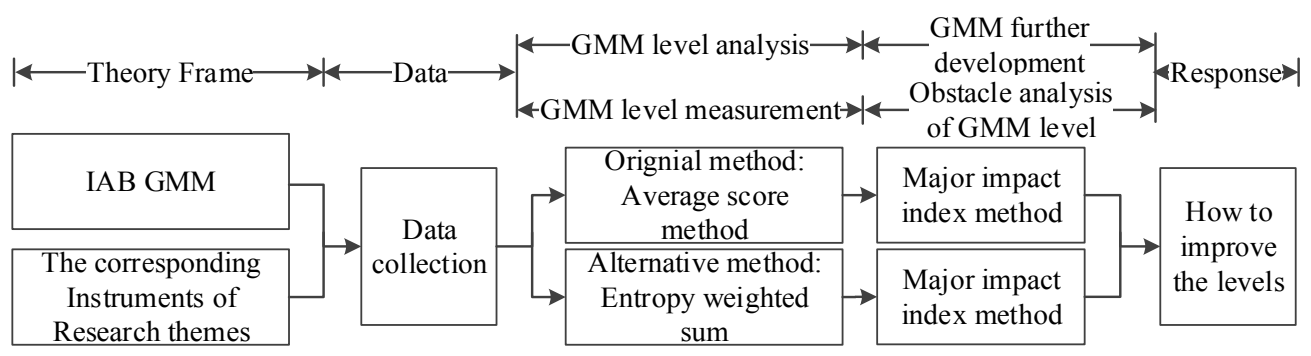

Figure 3. Research steps.

The Weisbord six-box model and the GMM have never been used within the context of the petroleum industry in China. This research focuses on the case of one main branch of PetroChina Company Limited (PetroChina), which is not only the largest and dominant producer and distributor of oil and gas in China, but also one of the largest oil companies in the world. In this context, the case shed light into organizational change management theory but also the quantitative analysis of an organization's internal evaluation stage at the operational level.

\section{Research Method}

The traditional GMM used the average score to evaluate the internal evolutionary growth in the organization, which deployed the same weight to all indicators without taking the indices' objectivity into account. This research applied the entropy method focusing on the indices' objective and realistic information to reach the GMM level, and further employed the top impact index formula [29-31] to quantitatively analyze the top internal barrier in the seven subsystems covered by Preziosi's extended instrument [42]. Thus far, the research established the systematic approach to quantitatively diagnose the organization's evolutionary growth level and the focused internal problem in each subsystem, which was a sound foundation to deliver the appropriate and rational suggestions to promote the organization's sustainable internal change.

\subsection{Average Score to the WSBGMM Level}

Analog to Charles McIntyre [27], the main steps for the average score to evaluate the WSBGMM level are shown as follows [27]:

(1) Calculating the average score of total sample:

Suppose there are $m$ units and $n$ indicators to be evaluated to establish the sum in Equation (1),

$$
Z F_{i}=\sum_{t=1}^{n} f_{s t}
$$

where $s=1,2 \cdots, m ; t=1,2 \cdots, n ; Z F_{s}=$ the score sum of $s^{\text {th }}$ sample, and $f_{s_{t}}=$ the $t^{\text {th }}$ index score of $s^{\text {th }}$ sample. Then, the average score of $m$ units was calculated in Equation (2),

$$
f=\sum_{s=1}^{m} Z F_{s} / m
$$

(2) Grading WSBGMM level:

When the average score was calculated, we applied it to grade the WSBGMM level.

Analog to the IAB GMM model [27], supposing that there was $K=5$ (where $A=1$ represents strong disagreement and $\mathrm{B}=9$ represents strong agreement) scaling, the scope of each level is shown in Table 1. 
Table 1. The scope of each level in the WSBGMM using the average score method.

\begin{tabular}{cccccc}
\hline Level & I & II & III & IV & V \\
\hline Scope & $n \times\left[1, \frac{1}{2}(1+3)\right)$ & $n \times\left[\frac{1}{2}(1+3), \frac{1}{2}(3+5)\right)$ & $n \times\left[\frac{1}{2}(3+5), \frac{1}{2}(5+7)\right)$ & $n \times\left[\frac{1}{2}(5+7), \frac{1}{2}(7+9)\right)$ & $n \times 9$ \\
\hline
\end{tabular}

$n$ represents the number of indicators in $m$ units. Source: Compiled by the authors analog to IAB GMM level calculation proposed by Charles McIntyre [27].

In the case of the average score method, it was assumed that the index weight probability of each sample at each level is equally allocated to generate the total sample level in the WSBGMM model. Actually, the index weight was objectively constrained by the sample score, which was the reason why we used another method, namely, the entropy method, to calculate the WSBGMM level to arrive at more accurate assessment results.

\subsection{Entropy Weight to the WSBGMM Level}

The entropy method [68] is an objective approach to reflect the disorder degree of information in not only information theory but also in the expansion of social and economic areas [66-68], in which the weights of individual indicators are determined by calculating the entropy and entropy weight. The greater the entropy, the smaller the corresponding entropy weight. If the entropy weight is zero, it provides no useful information to the decision-maker, and this indicator may be removed. The amount of useful information that the target provides to the decision-maker is objective. Therefore, using the entropy method to determine the index weights could reflect objective and realistic information of the WSBGMM level. The four main steps $[68,69]$ are shown as follows.

Step 1: The formation of the evaluation matrix:

Suppose there are also $m$ units and $n$ indicators to be evaluated to establish the original data matrix in Equation (3).

$$
R=\left(r_{s t}\right)_{m \times n}(s=1,2 \cdots, m ; t=1,2 \cdots, n)
$$

where $r_{s t}$ represents the actual value of the $t^{\text {th }}$ index of $s^{\text {th }}$ unit.

Step 2: The standardization of the evaluation matrix:

The following equation is used to normalize the matrix $B$,

$$
B=\left(b_{s t}\right)_{m \times n}(s=1,2 \cdots, m ; t=1,2 \cdots, n) \text { with } b_{s t}=\frac{r_{s t}-r_{\min }}{r_{\max }-r_{\min }}
$$

where $r_{\max }$ and $r_{\min }$ represent the maximum and minimum values respectively for the evaluation unit.

If indicator is the positive tropism (+),

$$
b_{s t}=\frac{r_{s t}-r_{\min }}{r_{\max }-r_{\min }}
$$

If indicator is the negative tropism $(-)$,

$$
b_{s t}=\frac{r_{\max }-r_{s t}}{r_{\max }-r_{\min }}
$$

Step 3: The calculation of the entropy:

The entropy of the system can be defined by using the following calculations:

$$
H_{t}=-\left[\sum_{s=1}^{m} f_{s t} \ln f_{s t}\right] / \ln m(s=1,2 \cdots, m ; t=1,2 \cdots, n)
$$


where $f_{s t}=b_{s t} / \sum_{s=1}^{m} b_{s t}$; if $f_{s t}=0$, redefine the $f_{s t}$ as

$$
f_{s t}=\left(1+b_{s t}\right) / \sum_{s=1}^{m}\left(1+b_{s t}\right)
$$

Step 4: The calculation of the entropy weight:

$$
w=\left(\omega_{t}\right)_{1 \times n}, \quad \omega_{t}=\left(1-H_{t}\right) /\left[n-\sum_{i=1}^{n} H_{t}\right] \text { with } \sum_{t=1}^{n} \omega_{t}=1
$$

Step 5: Use to Entropy weight to calculate the score of the WSBGMM level:

$$
s f=\sum_{i=1}^{n} \omega_{i} f_{i}
$$

where $\omega_{i}=$ the entropy weight of the $i^{\text {th }}$ index, and $f_{i}=$ the score of the $i^{\text {th }}$ index.

Step 6: Grade the level:

Analog to the average score method above, the entropy method to grade the WSBGMM level is shown in Table 2.

Table 2. The scope of the WSBGMM level using the entropy method.

\begin{tabular}{cccccc}
\hline Level & I & II & III & IV & V \\
\hline Score Scope & {$\left[1, \frac{1}{2}(1+3)\right)$} & {$\left[\frac{1}{2}(1+3), \frac{1}{2}(3+5)\right)$} & {$\left[\frac{1}{2}(3+5), \frac{1}{2}(5+7)\right)$} & {$\left[\frac{1}{2}(5+7), \frac{1}{2}(7+9)\right)$} & 9 \\
\hline
\end{tabular}

Source: Compiled by the authors analog to the grading thoughts of IAB GMM level proposed by Charles McIntyre [27].

\subsection{Targeted with Top Impact Influence Factor}

As stated previously, looking at the top impact barriers and taking targeted solutions in the organizational current level is a good way to promote the organizational sustainable path. This research used the major impact index formula [29-31] to generate and compare the impact extent of the indices, which are shown in Equation (9).

$$
A_{i}=\omega_{i} d_{i} / \sum_{i=1}^{n} \omega_{i} d_{i} \times 100 \%
$$

$A_{i}$ represents the indices' impact extent, $\omega_{i}$ represents the index entropy weight, $d_{i}$ represents the index standardization value, and $\mathrm{n}$ represents the index number in the evaluation system of the WSBGMM.

As to the use of the average method to calculate the top impact barriers, the index is allocated to the average weight. Thus, the top impact barrier formula with the average score method is shown in Equation (10).

$$
A_{i}=\frac{d_{i}}{\sum_{i=1}^{n} d_{i}} \times 100 \%
$$




\section{Research Results}

\subsection{Data Collection}

This data collected for this study was provided by the authors' consultation program and supported by PetroChina South Sulige Operating Company (PSSOC), located in Shaanxi province in China, which is a local large company of PetroChina's Changqing Oilfield Company. This company provides exploration and production of crude oil and natural gas. PetroChina Changqing Oilfield Company operates as a subsidiary of PetroChina Company Limited (PetroChina). As one of PetroChina's major oilfields, PetroChina Changqing Oilfield company covers five provinces in China, namely, Shaanxi, Gansu, Ningxia, Inner Mongolia, and Shanxi, and plays a pivotal role of supplying natural gas to more than ten big and medium size cities, including Beijing, Tianjin, and Shijiazhuang. PetroChina is the largest oil and gas producer and distributor, playing a dominant role in the oil and gas industry in China. PSSOC is a joint venture project between China National Petroleum Corporation and France's Total SA, in Northern Inner Mongolia. It started operations in 2012, and about 450 wells were drilled before production of the field could reach 3 billion cubic meters per year. China National Petroleum Corporation owns 51 percent of the project and will be the operator, while total SA holds the remaining 49 percent and will provide technology and management. This joint petro project is also the first time a Chinese company acts as the operator in a joint venture project in the petroleum field.

In order to investigate the internal motivational factors and evaluate the evolutionary growth level for PSSOC, a quantitative approach has been utilized. This approach addresses the research objectives through creation of concrete numerical descriptions of employee perceptions on a number of constructs by the adoption of Preziosi's organizational diagnosis questionnaire [42]. Data collection was conducted through the exhaust questionnaire surveys in PSSOC. The survey method was selected because there was little control over behavioral events, and the focus was to identify and develop a contemporary phenomenon within a real life context. Quantitative data collected from the distributed questionnaires were analyzed utilizing the SPSS 22 software. Cronbach's alpha test was conducted to assess reliability of the scale items [70]. Descriptive statistics described and summarized profiles of the entire sample.

The questionnaire issue and collection is shown in Table 3.

Table 3. Questionnaire issue and collection in PSSOC.

\begin{tabular}{|c|c|c|c|c|c|c|c|}
\hline No. & $\begin{array}{c}\text { Investigation } \\
\text { Time in } 2015\end{array}$ & Location & Distributed & Response & Valid & Response Rate \% & Valid Rate \% \\
\hline 1 & March,24 & Headquarter in $\mathrm{Xi}^{\prime}$ an, China & $\mathrm{N}=113$ & $\mathrm{~N}=109$ & $\mathrm{~N}=109$ & 96.5 & 100 \\
\hline 2 & April, 11 & $\begin{array}{l}\text { Headquarter in northern } \\
\text { Inner Mongolia, China }\end{array}$ & $\mathrm{N}=66$ & $\mathrm{~N}=59$ & $\mathrm{~N}=59$ & 89.4 & 100 \\
\hline 3 & April, 11 & $\begin{array}{c}\text { Field in in northern Inner } \\
\text { Mongolia, China }\end{array}$ & $\mathrm{N}=12$ & $\mathrm{~N}=12$ & $\mathrm{~N}=12$ & 100 & 100 \\
\hline
\end{tabular}

Source: Compiled by the authors. Current total population number of PSSOC $=180$ people, sample $\mathrm{N}=180$.

The instrument descriptive statistics of seven subsystems is shown in Table 4.

According to Table 4, by the consideration of Preziosi's instrument data interpretation [42], the simplest diagnosis would be to assess the amount of variance for each of the five variables in relation to a score of 5 , which is the neutral point. Scores below 5 would indicate that there is a problem with the respective organizational functions. The closer the score moves to 1 , the more severe the respective problem. Scores above 5 would indicate that there is no problem, and a score of 9 would indicate optimum functioning of the respective organizational function. Thus, the mean score of Rewards (6.80) and Attitude Toward Change (6.76) were a little further away from the score of 9 than the other six subsystems, which indicated a potential problem area in the PSSOC sample. Additionally, the average of Leadership (7.43) was the maximum, which indicates the optimum organizational functioning at the current level. 
Table 4. Data descriptive statistics.

\begin{tabular}{lccccc}
\hline \multicolumn{1}{c}{ 7 Subsystems } & N & Means & Means Standard Error & Standard Deviation & Variance \\
\hline Purpose (PUR) & 180 & 7.17 & 0.099 & 1.332 & 1.773 \\
Relationships (REL) & 180 & 7.24 & 0.097 & 1.306 & 1.705 \\
Helpful Mechanisms (HM) & 180 & 7.28 & 0.101 & 1.357 & 1.842 \\
Rewards (REW) & 180 & 6.80 & 0.131 & 1.752 & 3.07 \\
Structure (STR) & 180 & 6.92 & 0.127 & 1.206 & 1.897 \\
Leadership (LEA) & 180 & 7.43 & 0.090 & 1.342 & 1.8 \\
Attitude Toward Change (ATC) & 180 & 6.76 & 0.100 & & \\
Total & 180 & & &
\end{tabular}

At the same time, according to the statistics principle [71], standard deviation referred to the variation degree between the samples' observed values, which indicated the observed fluctuations. The standard deviation in Table 4 shows that all standard deviations are below 2 [71,72], which indicates that PSSOC employee attitude to organizational function was at a relatively consistent level and not in a state of fluctuation. The standard deviation describes the degree of variation between the values observed in the sample, indicating the size of the observed fluctuations of less than 2 for the attitude of employee, which means that the observations were consistent and centered around this dimension.

\subsection{Data Quality}

The reliability analysis and validity for each of the composite constructs of the questionnaires of this research were examined to test data quality [71-73]. Reliability of the scale examines its internal consistency by calculating Cronbach's alpha. Therefore, to explore the reliability of the constructs in order to design good scales for measurement, data were analyzed using SPSS 22.0 software (SPSS 22.0.0.1, International Business Machines Corporation, Beijing, China). The processes are shown in Tables S1-S4 in the supplement material.

Additionally, to estimate the reliability of the items for each construct, internal consistency methods include the value of item-to-total correlation and Cronbach's alpha value [71,74]. A minimum value of item-to-total correlation values should be greater than 0.40 , and item-to-total correlation values in each construct at the 0.05 level are of reliable significance [71,75].

Hence, as unreliability in these items would mean that they could not be used in any future examinations, the item-to-total correlations and Cronbach's alpha values for items within the seven components have been analyzed (see Table 5).

All internal consistency reliability based on Cronbach's alpha for measurement items was found to be greater than 0.7 and considered to be good and acceptable, indicating a high degree of internal consistency $[71,74,75]$. 
Table 5. Preziosi (1980) [42] questionnaire development with PSSOC sample.

\begin{tabular}{|c|c|c|c|c|c|c|}
\hline Subsystem & $\begin{array}{l}\text { Code in Preziosi's } \\
\text { Instrument }\end{array}$ & Item Description & Cronbach's Alpha & $\begin{array}{l}\text { Cronbach's Alpha } \\
\text { If Item Deleted }\end{array}$ & $\begin{array}{l}\text { Item to Total } \\
\text { Correlation }\end{array}$ & $\begin{array}{l}\text { New Code after } \\
\text { Item Test }\end{array}$ \\
\hline \multirow{5}{*}{ Purpose (PUR) } & Q1 & The goals of this organization are clearly stated. & \multirow{5}{*}{0.803} & 0.731 & 0.694 & PUR-1 \\
\hline & Q8 & $\begin{array}{l}\text { I am personally in agreement with the stated goals of my } \\
\text { work unit. }\end{array}$ & & 0.761 & 0.646 & PUR-2 \\
\hline & Q15 & I understand the purpose of this organization. & & 0.726 & 0.758 & PUR-3 \\
\hline & Q22 & The structure of my work unit is well designed. & & 0.723 & 0.717 & PUR-4 \\
\hline & Q29 & I want to complete the task with less energy and time. & & 0.880 & 0.325 & Deleted \\
\hline \multirow{5}{*}{ Relationships (REL) } & Q4 & My relationship with my supervisor is a harmonious one. & \multirow{5}{*}{0.820} & 0.792 & 0.607 & REL-1 \\
\hline & Q11 & $\begin{array}{l}\text { I can always talk with someone at work if I have a } \\
\text { work-related problem. }\end{array}$ & & 0.755 & 0.707 & REL-2 \\
\hline & Q18 & $\begin{array}{l}\text { My relationship with members of my work group are } \\
\text { friendly as well as professional. }\end{array}$ & & 0.797 & 0.570 & REL-3 \\
\hline & Q25 & $\begin{array}{l}\text { I have established the relationships that I need to do my } \\
\text { job properly. }\end{array}$ & & 0.782 & 0.633 & REL-4 \\
\hline & Q32 & $\begin{array}{l}\text { There is no evidence of unresolved conflict in this } \\
\text { organization. }\end{array}$ & & 0.796 & 0.601 & REL-5 \\
\hline \multirow{5}{*}{$\begin{array}{l}\text { Helpful Mechanisms } \\
\qquad(\mathrm{HM})\end{array}$} & Q6 & $\begin{array}{l}\text { My immediate supervisor has ideas that are helpful to me } \\
\text { and my work group. }\end{array}$ & \multirow{5}{*}{0.854} & 0.839 & 0.607 & HM-1 \\
\hline & Q13 & I have the information that I need to do a good job. & & 0.810 & 0.718 & HM-2 \\
\hline & Q20 & $\begin{array}{l}\text { This organization has adequate mechanisms for binding } \\
\text { itself together. }\end{array}$ & & 0.798 & 0.761 & HM-3 \\
\hline & Q27 & $\begin{array}{l}\text { Other work units are helpful to my work unit whenever } \\
\text { assistance requested. }\end{array}$ & & 0.854 & 0.546 & HM-4 \\
\hline & Q34 & This organization's planning and control development. & & 0.807 & 0.729 & HM-5 \\
\hline \multirow{5}{*}{ Rewards (REW) } & Q5 & My job offers me the opportunity to grow as a person. & \multirow{5}{*}{0.914} & 0.896 & 0.774 & REW-1 \\
\hline & Q12 & $\begin{array}{l}\text { The pay scale and benefits of this organization treat each } \\
\text { employee equitably. }\end{array}$ & & 0.908 & 0.713 & REW-2 \\
\hline & Q19 & The opportunity for promotion exists in this organization. & & 0.886 & 0.822 & REW-3 \\
\hline & Q26 & $\begin{array}{l}\text { The salary that I receive is commensurate with the job that } \\
\text { I perform. }\end{array}$ & & 0.904 & 0.739 & REW-4 \\
\hline & Q33 & All tasks to be accomplished are associated with incentives. & & 0.878 & 0.859 & REW-5 \\
\hline
\end{tabular}


Table 5. Cont.

\begin{tabular}{|c|c|c|c|c|c|c|}
\hline Subsystem & $\begin{array}{l}\text { Code in Preziosi's } \\
\text { Instrument }\end{array}$ & Item Description & Cronbach's Alpha & $\begin{array}{l}\text { Cronbach's Alpha } \\
\text { If Item Deleted }\end{array}$ & $\begin{array}{l}\text { Item to Total } \\
\text { Correlation }\end{array}$ & $\begin{array}{l}\text { New Code after } \\
\text { Item Test }\end{array}$ \\
\hline \multirow{5}{*}{ Structure (STR) } & Q2 & The division of labor of this organization is flexible. & \multirow{5}{*}{0.918} & 0.902 & 0.785 & STR-1 \\
\hline & Q9 & $\begin{array}{l}\text { The division of labor of this organization is conducive to } \\
\text { reaching its goals. }\end{array}$ & & 0.893 & 0.823 & STR-2 \\
\hline & Q16 & $\begin{array}{l}\text { The manner in which work tasks are divided is a } \\
\text { logical one. }\end{array}$ & & 0.891 & 0.836 & STR-3 \\
\hline & Q23 & The structure of my work unit is well designed. & & 0.907 & 0.753 & STR-4 \\
\hline & Q30 & $\begin{array}{l}\text { The division of labor of this organization helps its efforts to } \\
\text { reach its goals. }\end{array}$ & & 0.905 & 0.778 & STR-5 \\
\hline \multirow{5}{*}{ Leadership (LEA) } & Q3 & My immediate supervisor is supportive of my efforts. & \multirow{5}{*}{0.833} & 0.843 & 0.464 & Deleted \\
\hline & Q10 & The leadership norms of this organization help its progress. & & 0.790 & 0.672 & LEA-1 \\
\hline & Q17 & $\begin{array}{l}\text { This organization's leadership efforts result in the } \\
\text { organization's fulfillment of its purposes. }\end{array}$ & & 0.782 & 0.702 & LEA-2 \\
\hline & Q24 & $\begin{array}{l}\text { It is clear to me whenever my boss is attempting to guide } \\
\text { my work efforts. }\end{array}$ & & 0.801 & 0.629 & LEA-3 \\
\hline & Q31 & $\begin{array}{l}\text { I understand my boss's efforts to influence me and the } \\
\text { other members of the work unit. }\end{array}$ & & 0.775 & 0.715 & LEA-4 \\
\hline \multirow{5}{*}{$\begin{array}{l}\text { Attitude Toward } \\
\text { Change (ATC) }\end{array}$} & Q7 & This organization is not resistant to change. & \multirow{5}{*}{0.723} & 0.633 & 0.604 & ATC-1 \\
\hline & Q14 & $\begin{array}{l}\text { The organization has not brought in enough new policy } \\
\text { and process management. }\end{array}$ & & 0.732 & 0.361 & Deleted \\
\hline & Q21 & This organization favors change. & & 0.602 & 0.645 & ATC-2 \\
\hline & Q28 & I can decide how to complete my work once in a while. & & 0.716 & 0.372 & Deleted \\
\hline & Q35 & $\begin{array}{l}\text { The organization is capable of upgrading itself and } \\
\text { doing better. }\end{array}$ & & 0.680 & 0.474 & Deleted \\
\hline
\end{tabular}

Source: Compiled by the authors with SPSS 22. The "deleted" classification represents items whose corresponding item did not meet the critical value of reliability and validity analysis [75]. 


\subsection{Result I-Average Score Method}

\subsubsection{Grading the WSBGMM Level-Average Score Method}

Based on the above questionnaire development in Table 5, 30 items of 35 items were acquired as a sound foundation to analyze the WSBGMM level from the seven subsystems. By applying Equations (1) and (2) in Section 3.1, the average score of 180 samples in PSSOC was calculated, where $f=213.156$. At the same time, following the grading guidelines in above Table 1, the WSBGMM level of PSSOC was established in Table 6. The average score of PSSOC impinges on Level IV; further, the evolutionary growth of PSSOC is shown in Figure 4.

Table 6. The WSBGMM level of PSSOC using average score method.

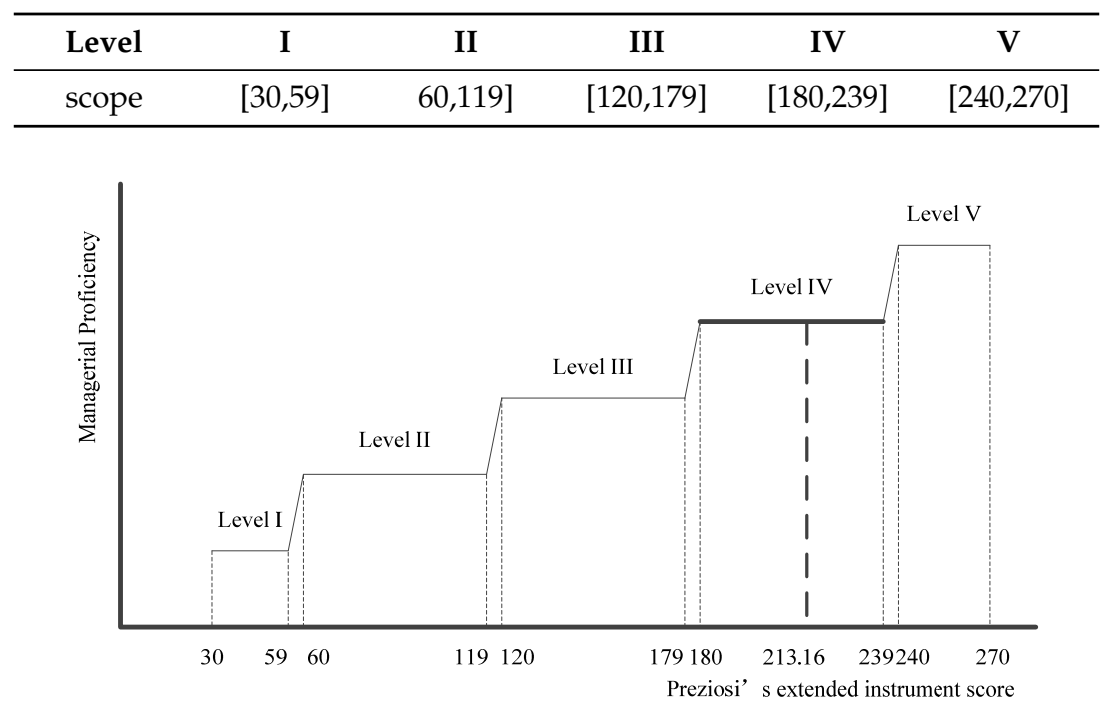

Figure 4. The evolutionary growth of PSSOC using average score method analog to IAB GMM [27].

Thus, PSSOC needed an appropriate way to target specific problem areas in order to solve the obstacles to improve the internal evolutionary growth and to realize sustainable organizational change.

\subsubsection{Top Impact Influence Factors-Average Score Method}

In order to look for the top impact influence factors, Equation (10) in Section 3.3 was deployed to generate and compare the impact extent of the 30 items in the seven subsystems of Preziosi's instrument framework [42]. The indices were then placed in descending order of their frequencies. The lowest frequency indices were the top impact influence factors for PSSOC, which will be the focus of our attention. The results are shown in Table 7.

Table 7. Top impact barriers based on the average score method.

\begin{tabular}{ccccccccccc}
\hline Index & PUR-1 & PUR-2 & PUR-3 & PUR-4 & REL-1 & REL-2 & REL-3 & REL-4 & REL-5 & HM-1 \\
\hline Frequency & 126 & 155 & 162 & 140 & 146 & 142 & 136 & 115 & 104 & 147 \\
Frequency rate\% & 70 & 86.1 & 90 & 77.8 & 81.1 & 78.9 & 75.6 & 63.9 & 57.8 & 81.7 \\
Index & HM-2 & HM-3 & HM-4 & HM-5 & REW-1 & REW-2 & REW-3 & REW-4 & REW-5 & STR-1 \\
Frequency & 141 & 120 & 149 & 138 & 96 & 139 & 95 & 109 & 109 & 112 \\
Frequency rate\% & 78.3 & 66.7 & 82.8 & 76.7 & 53.3 & 77.2 & 52.8 & 60.6 & 60.6 & 62.2 \\
Index & STR-2 & STR-3 & STR-4 & STR-5 & LEA-1 & LEA-2 & LEA-3 & LEA-4 & ATC-1 & ATC-2 \\
Frequency & 125 & 112 & 129 & 146 & 143 & 134 & 133 & 138 & 74 & 98 \\
Frequency rate\% & 69.4 & 62.2 & 71.7 & 81.1 & 79.4 & 74.4 & 73.9 & 76.7 & 41.1 & 54.4 \\
\hline
\end{tabular}

"Index" item in Table 7 is the "New code after item test" item in Table 5, and is also in line with "Code in Preziosi's instrument" item in Table 5. For example, ATC-1 in Table 7 is ATC-1 in Table 5, and is also in line with Q7 in Table 5. 
From Table 7 above, the three lowest frequency indices are ATC-1, REW-3, and REW-1 (as described in Table 5), which indicates that these three factors are top influence factors and should be considered in the overall assessment of PSSOC. From the view point of each subsystem, the top influence factor in the subsystem was PUR-2, the top influence factor in the Relationships subsystem was REL-5, the top influence factor in the Helpful Mechanisms subsystem was HM-3, the top influence factor in the Rewards subsystem was REW-1, the top influence factors in the Structure subsystem were STR-1 and STR-3, the top influence factor in the Leadership subsystem was LEA-2, and the top influence factor in the Attitude Toward Change subsystem was ATC-1.

\subsection{Result II-Entropy Method}

\subsubsection{Entropy Weight}

The authors constructed the evaluation matrix and matrix standardization with Equations (3) and (4) using raw data. They then used Equations (5)-(7) to work with the standardization data. The results of the entropy weights of indices are shown in Table 8 . Table 8 clearly shows that the index weights are different from each other. This also supports the aforementioned research method. In other words, all indicators should take the index objectivity into account, rather than always follow the same weight rules of traditional GMM. The standard data processes are shown in Table 44 in the supplement material.

Table 8. Entropy weight.

\begin{tabular}{ccccccccccc}
\hline Index & PUR-1 & PUR-2 & PUR-3 & PUR-4 & REL-1 & REL-2 & REL-3 & REL-4 & REL-5 & HM-1 \\
\hline Entropy weight & 0.028 & 0.014 & 0.017 & 0.029 & 0.027 & 0.027 & 0.028 & 0.036 & 0.041 & 0.025 \\
Index & HM-2 & HM-3 & HM-4 & HM-5 & REW-1 & REW-2 & REW-3 & REW-4 & REW-5 & STR-1 \\
Entropy weight & 0.027 & 0.035 & 0.023 & 0.027 & 0.064 & 0.033 & 0.039 & 0.044 & 0.043 & 0.044 \\
Index & STR-2 & STR-3 & STR-4 & STR-5 & LEA-1 & LEA-2 & LEA-3 & LEA-4 & ATC-1 & ATC-2 \\
Entropy weight & 0.034 & 0.045 & 0.029 & 0.024 & 0.031 & 0.034 & 0.023 & 0.027 & 0.055 & 0.043 \\
\hline
\end{tabular}

"Index" item in Table 8 is the "New code after item test" item in Table 5, and is also in line with "Code in Preziosi's instrument" item in Table 5. For example, REW-3 in Table 8 is REW-3 in Table 5, and is also in line with Q19 in Table 5.

\subsubsection{Grading the WSBGMM Level-Entropy Method}

Using Equation (9), the average score of PSSOC sample was 7.022. At the same time, according to Table 2, the scope of the WSBGMM level using the entropy method is established in Table 9. Obviously, the average score of PSSOC still impinges on Level IV. The evolutionary growth of PSSOC is shown in Figure 5. In order to move to a higher level, PSSOC needs to seek the specific top potential factors which hindered PSSOC from pursuing sustainable development.

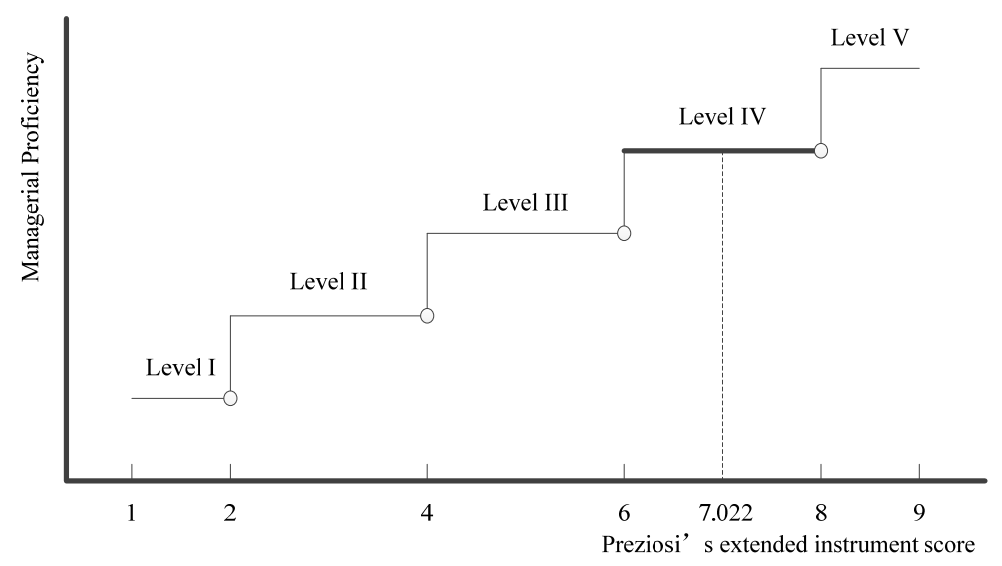

Figure 5. The evolutionary growth of PSSOC using the entropy method. 
Table 9. The WSBGMM level of PSSOC using entropy method.

\begin{tabular}{cccccc}
\hline Level & I & II & III & IV & V \\
\hline Scope & {$[1,2)$} & {$[2,4)$} & {$[4,6)$} & {$[6,8)$} & {$[8,9]$} \\
\hline
\end{tabular}

\subsubsection{Top Impact Influence Factors—Entropy Method}

Analog to Section 4.3.2, this research employed Equation (9) in Section 3.3 to assess the indices' impact extent and compare their frequencies. The lowest frequency influence factors are the top impact barriers which should receive closer attention. The result is shown in Table 10.

Table 10. Top impact barriers based on entropy method.

\begin{tabular}{ccccccccccc}
\hline Index & PUR-1 & PUR-2 & PUR-3 & PUR-4 & REL-1 & REL-2 & REL-3 & REL-4 & REL-5 & HM-1 \\
\hline Frequency & 83 & 4 & 6 & 101 & 77 & 77 & 88 & 124 & 152 & 50 \\
Frequency rate\% & 46.1 & 2.2 & 3.3 & 56.1 & 42.8 & 42.8 & 48.9 & 68.9 & 84.4 & 27.8 \\
Index & HM-2 & HM-3 & HM-4 & HM-5 & REW-1 & REW-2 & REW-3 & REW-4 & REW-5 & STR-1 \\
Frequency & 71 & 145 & 39 & 61 & 166 & 139 & 146 & 149 & 160 & 155 \\
Frequency rate $\%$ & 39.4 & 80.6 & 21.7 & 33.9 & 92.2 & 77.2 & 81.1 & 82.8 & 88.9 & 86.1 \\
Index & STR-2 & STR-3 & STR-4 & STR-5 & LEA-1 & LEA-2 & LEA-3 & LEA-4 & ATC-1 & ATC-2 \\
Frequency & 133 & 156 & 97 & 17 & 129 & 137 & 23 & 62 & 147 & 148 \\
Frequency rate $\%$ & 73.9 & 86.7 & 53.9 & 9.4 & 71.7 & 76.1 & 12.8 & 34.4 & 81.7 & 82.2 \\
\hline
\end{tabular}

Form Table 10 above, the three lowest frequencies are PUR-2, PUR-3, and STR-5 (as described in Table 5). However, the other three influence factors LEA-3, HM-4, and HM-1 were also substantially below the rest of the indices. Using the entropy method, six influence factors were identified and should be focused on as specific problem areas for PSSOC.

From the viewpoint of each subsystem, the influence factors in the Purpose subsystem were PUR-2 and PUR-3, the influence factors in the Relationships subsystem were REL-1 and REL-2, the influence factors in the Helpful Mechanisms subsystem were HM-1 and HM-4, the influence factor in the Rewards subsystem was REW-3, the influence factor in the Structure subsystem was STR-5, the influence factor in the Leadership subsystem was LEA-3, and the influence factor in the Attitude Toward Change subsystem was ATC-1, as reviewed in Table 5.

\subsubsection{Results I and II Comparison}

Results I and II employed different methods with the same framework, and arrived at the same evolutional level in the WSBGMM model for PSSOC. However, they were divergent on evaluating the top impact influence factors and capturing specific problem factors in the seven subsystems. The top impact influence factors using both methods are summarized in Tables 11 and 12 .

Table 11. Compared top impact influence factors using two compared methods to look at the entire system.

\begin{tabular}{ccccc}
\hline \multirow{2}{*}{ No. } & \multicolumn{2}{c}{ Entropy Method } & \multicolumn{2}{c}{ Average Score Method } \\
\cline { 2 - 5 } & Influence Factors & Frequency Rate & Influence Factors & Frequency Rate \\
\hline 1 & PUR-2 & 2.2 & ATC-1 & 41.1 \\
2 & PUR-3 & 3.3 & REW-3 & 52.8 \\
3 & STR-5 & 9.4 & REW-1 & 53.3 \\
4 & LEA-3 & 12.8 & ATC-2 & 54.4 \\
5 & HM-4 & 21.7 & REL-5 & 57.8 \\
6 & HM-1 & 27.8 & REW-4 & 60.6 \\
7 & HM-5 & 33.9 & REW-5 & 60.6 \\
8 & LEA-4 & 34.4 & STR-1 & 62.2 \\
9 & HM-2 & 39.4 & STR-3 & 62.2 \\
\hline
\end{tabular}


Table 12. Compared top impact influence factors using two compared methods within each subsystems.

\begin{tabular}{ccc}
\hline Subsystems & Method & Influence Factors \\
\hline \multirow{2}{*}{ Purpose } & Entropy method & PUR-2, PUR-3 \\
& Average Score method & PUR-1, PUR-4 \\
\hline \multirow{2}{*}{ Relationship } & Entropy method & REL-1, REL-2 \\
& Average Score method & REL-5, REL-4 \\
\hline \multirow{2}{*}{ Help Mechanisms } & Entropy method & HM-4, HM-1 \\
& Average Score method & HM-3, HM-5 \\
\hline \multirow{2}{*}{ Rewards } & Entropy method & REW-2, REW-3 \\
& Average Score method & REW-1, REW-3 \\
\hline \multirow{2}{*}{ Structure } & Entropy method & STR-5, STR-4 \\
& Average Score method & STR-1, STR-3 \\
\hline \multirow{2}{*}{ Leadership } & Entropy method & LEA-3, LEA-4 \\
& Average Score method & LEA-2, LEA-3 \\
\hline \multirow{2}{*}{ Attitude Toward Change } & Entropy method & ATC-1 \\
& Average Score method & ATC-1 \\
\hline
\end{tabular}

Source: Compiled by the authors.

As to the different results when using the two methods, we have sufficient reason to support the result of the entropy method and its method justification in Section 3; the average weight was subjectively allocated to the indices using the average score method without taking the objectivity of index information of the entropy method into consideration. We can therefore claim that the result of the top impact influence factors using the entropy method should be used to analyze specific internal problem areas and propel evolutional growth of an organization. Additionally, we can state that entropy method is a considerable alternative approach to objectively and accurately targeting specific influence factors of evolutionary growth levels within the WSBGMM framework, and this may be appropriate not only in the IAB GMM framework but also in the extended GMM and the framework adoption of IAB GMM.

\subsection{Discussion}

In order to achieve sustainable organizational change, PSSOC should recognize the importance of the four subsystems and adopt necessary countermeasures to settle the corresponding primary internal factors at the current level, including (a) Purpose; (b) Structure; (c) Leadership and (d) Helpful Mechanisms.

(A) Purpose: PSSOC should create a clear organizational purpose (PUR-2 in Table 5) and support the changes necessary for reaching desired future outcomes (PUR-3 in Table 5). Organizations need to share their organizational purpose to move toward the desired direction and sustain the adaptation process to create a future for the organization. If employees are not absolutely sure about their organization's purpose, they will make their own presumptions and projections, which often lead to wrong actions. The shared organizational purpose creates consistent attitudes among employees which will guide their decisions about their cognitive level of support for needed change initiatives [76]. Therefore, the organizational purpose should be salient to all members in the organization, with members understanding that a clear organizational purpose has been articulated and that the leadership of the organization shares that purpose. Additionally, a company should build an environment where all employees fully understand the organizational purpose. Leadership will have to clarify what the organizational purpose is with regard to each employee's position, and ensure that the resources to execute the organizational purpose are in place to accomplish the desired organizational goal. 
(B) Structure: Weisbord [26] stated that structure refers to a fit between the purpose and the internal structure of an organization. In other words, internal structure refers to the degree of authority in an organization and how work is being apportioned [77]. This structure could then provide specific avenues to implement internal change processes in particular situations, considering management support and time constraints [12].

For PSSOC, avoiding the influence factor (STR-5 in Table 5) could be a central problem to the sustainability of organizational change. The authors therefore suggested that PSSOC should (1) adjust the department structure and the corresponding labor division; (2) build communication mechanisms; and (3) allocate the scopes and responsibilities of various departments in a way to avoid overlapping and therefore enhance the organization's departmental efficiencies. At the same time, in order to drive structural change, the organization may implement pilot projects, experimental units, technology supports, and special task forces. Once a clear direction of how to implement change is recognized, a need to design specifications for departmental change may arise and be directed to specify those needs and implement action plans.

(C) Leadership: Weisbord [26] proposed that organizational leadership should focus on whether leaders define purposes, whether they embody purposes in their programs, and what the normative style of leadership is. Research has shown that effective leadership is the most important factor for successful change, and organizational success or failure depends on the ability of its leaders [7880]. Whenever the challenges of managing organizational change for sustainability is involved, effective leaders who are competent to embrace and facilitate change are required to influence their subordinates [81].

As for the influence factor (LEA-3 in Table 5) of leadership in PSSOC, effective leaders should influence the way their subordinates think and introduce new processes into the organization by influencing the understanding of current structures and shaping values to facilitate internal comprehension of the need for organizational growth [82,83]. As such, the following activities could be implemented: (1) in-depth understanding of a department's current situation; (2) fulfilling employee's needs; (3) strengthening communication and interaction among staff in the within and among departments; and (4) motivating staff to develop a passion toward work goal achievements by participating in decision processes.

(D) Helpful Mechanisms: Weisbord [26] proposed that helpful mechanisms mainly referred to whether these mechanisms help or hinder the accomplishment of organizational objectives. Effective sustainable change requires mechanisms that allocate sufficient resources to support a process $[41,81,84]$. This include team support policies and functional support for projects, which are critical to successfully managing change within organizations and to track work systems and identify problem areas.

As for the influence factors (HM-4 and HM-1 in Table 5) of helpful mechanisms in PSSOC, a key task for leaders is not only to allow the clear goal for the personal and group implementation, but to find a balance and collaboration between the resources deployed in different departments. PSSOC also needs to overcome resistance to sustainable growth by sustaining the goal and confidence of staff and by ensuring that their organization has sufficient resources to support such change.

Helpful mechanisms should support the implementation of organizational change. When employees feel that they have helpful mechanisms, such as resource support for change, there is an increased likelihood that organizational achievements will increase and that sustainable change implementation will be realized [22,81,85-87]. Employees' perceptions of the extent to which their organization has sufficient helpful mechanisms to achieve change (e.g., readily available finance, communication technologies, flexible systems, and responsive training and education), and the degree to which they can actively and genuinely participate in the process, are significant factors in accomplishing successful change [22,81,85-87].

Last but not least, the above statement was the central problem areas for PSSOC, and it was not surprising that sustainable organizational change was a system change that needed the synergy 
of seven subsystems in the WSBGMM framework. This system also implies not only that sufficient support for targeting a problem area is needed to provide implementing agencies to ensure effective change [34,41], but also that time was a necessary resource to successfully transform an entire system $[87,88]$, which allowed employees to participate in the change process and successfully bring their activities to the process of the whole WSBGMM system.

\section{Conclusions}

This study discusses an integrated diagnostic framework to manage an organization's sustainable growth and attempts to design and quantify an evaluation system for organizational internal and evolutionary growth and the corresponding targeted influence factors. It opens a door to future research in the theory-testing and application areas of sustainable organizational change. This study proposes a new systematic integrated approach to supplement the quantitative framework and methods in the organizational diagnosis for sustainability applied to the case of PSSOC.

Building truly sustainable organizations is difficult and often requires a significant shift in the internal identity of the firm, as well as in its core structure and processes. Embracing sustainability implies changing deeply embedded, taken-for-granted assumptions about what organizational leaders, structures, and relationships do and how they operate at the current level. Organizational change for sustainability should focus on (a) an internal problem areas diagnosis and (b) a stage of internal evolutionary growth. As one of the outstanding organizational change models, the Weisbord six-box model and Preziosi's extended instrument focuses on internal organizational problem areas, which are widely applied in education, churches, and the automobile industry to show the simple but critical path for organizational diagnosis. IAB GMM has similar features to assess a quantitative evaluation of the organizational internal and evolutionary growth with the average score method. Therefore, this research built an integrated framework of organizational change for sustainability, containing the extended instrument of the Weisbord six-box model and the IAB GMM generic framework (WSBGMM). This framework also includes the seven subsystems of Purposes, Structure, Relationships, Rewards, Leadership, Helpful Mechanisms, and Attitude Toward Change. Along with the adoption of a questionnaire based on Preziosi's organizational diagnosis instrument, this research system assessed the growth level of the WSBGMM, employed a case sample, and used the compared results of the average score method and the entropy method for validation. It analyzed the major internal impact influence factors to promote sustainable growth throughout the process of change.

Case studies showed that the two compared methods confirmed the same grade level of the integrated WSBGMM framework. There was a best-practices approach for targeting the integral evolutionary growth level to respond to the needs of organizational change for sustainability. The major influence factors of the WSBGMM are: (a) Purpose, which referred to staff disagreeing with the stated goals of work units (PUR-2 in Table 5) and personally not understanding the organizational purpose (PUR-3 in Table 5); (b) Structure, which referred to labor division (STR-5 in Table 5); (c) Leadership, which referred to unclear leadership (LEA-3 in Table 5); and (d) Helpful Mechanisms, which referred to unclear goal setting from immediate supervisors (HM-1 in Table 5).

At last, a few comments should be made that this research provided a theoretical framework and an application method to assess and evaluate both an organizational internal diagnosis method and a growth management model. This research can be implemented to evaluate and grade the organizational internal and evolutionary growth at a global, national, and local branch of large companies with the corresponding sequential data warehouse in various industries. A limitation of this research is due to the sequential data boundary when creating a systematic analysis to conceptualize organizational internal evolutionary growth. A possible future research project may be to enlarge the dynamics data collection to analyze the organizational internal evolutionary growth at both the branch and headquarters of a company. 
Supplementary Materials: The following are available online at www.mdpi.com/2071-1050/8/4/301/s1, Table S1: Organizational diagnosis questionnaire from Robert C. Preziosi, Table S2: Descriptive statistics, Table S3: The questionnaire for growth management model based on Weisbord's six-box organizational model (WSBGMM), Table S4: Standard data of entropy method.

Acknowledgments: This research is supported by the National Natural Science Fundation of China (NO. 71301013); the Humanity and Social Science Program Foundation of Ministry of Education of China (NO. 13YJA790150); the China ASC Fund (NO. asc-kt2014022 and asc-kt2014023); the China Scholarship Council; the Shaanxi Nature Science Fund (NO. 2014JM2-7140); the Shaanxi Social Science Fund (NO. 2014HQ10, NO. 2015Z071, and NO. 2015Z075); the Xi'an Science Technology Burea Fund (NO.CXY1512(2)); the Special Fund for Graduate Student Education Reform of Central College, Chang'an University (NO. jgy16062); and the Special Fund for Basic Scientific Research of Central College (Humanities and Social Sciences), Chang'an University (NO. 0009-2014G6285048, NO.310828155031, NO.310828160661 and NO.310828160663).

Author Contributions: Jingxiao Zhang and Hui Li conducted the interviews, analyzed the data and contributed to drafting the paper. Zhang and Li contributed to the concept and design of the paper, and Schmidt contributed useful advice and modified the paper. Zhang was in charge of the final version of the paper.

Conflicts of Interest: The authors declare no conflict of interest.

\section{Abbreviations}

The following abbreviations are used in this manuscript:

$\begin{array}{ll}\text { WSBGMM } & \text { Weisbord six-box model and GMM } \\ \text { PetroChina } & \text { PetroChina Company Limited } \\ \text { PSSOC } & \text { PetroChina South Sulige Operating Company } \\ \text { GMM } & \text { Growth management model } \\ \text { IAB } & \text { Industry Advisory Board }\end{array}$

\section{References}

1. Kozioł, L.; Kozioł, W.; Wojtowicz, A.; Pyrek, R. Diagnosis of innovation enterprises-Study theoretical and empirical results. Procedia Soc. Behav. Sci. 2015, 175, 137-145. [CrossRef]

2. Sashkin, M. Organizational diagnosis: A workbook of theory and practice. Group Organ. Manag. 1979, 4, 126-129. [CrossRef]

3. McFillen, J.M.; O'Neil, D.A.; Balzer, W.K.; Varney, G.H. Organizational diagnosis: An evidence-based approach. J. Chang. Manag. 2013, 13, 223-246. [CrossRef]

4. Ramos, C.V.Q.; Rees, C.J. The current state of organization development: Organizational perspectives from western europe. Organ. Dev. J. 2008, 26, 67-80.

5. Gallicano, T.D. Internal conflict management and decision making: A qualitative study of a multitiered grassroots advocacy organization. J. Public Relat. Res. 2013, 25, 368-388. [CrossRef]

6. Kubrak, A.; Koval, K.; Kavaliauskas, V.; Sakalas, A. Organizational structure forming problems in modern industrial enterprise. Inzinerine Ekono. Eng. Econ. 2007, 1, 103-109.

7. Keeffe, M.J.; Darling, J.R. Transformational crisis management in organization development: The case of talent loss at microsoft. Organ. Dev. J. 2008, 26, 43-58. [CrossRef]

8. Chang, H.; Hung, C.; Wong, K.; Lee, C. Using the balanced scorecard on supply chain integration performance-A case study of service businesses. Serv. Bus. 2013, 7, 539-561. [CrossRef]

9. Sahoo, C.K.; Sharma, R. Managing grassroot-level change in an indian psu: The role of people-centric strategies. South Asian J. Manag. 2015, 22, 28-47.

10. Andersson, G. Resisting organizational change. Int. J. Adv. Corp. Learn. 2015, 8, 48-51. [CrossRef]

11. Lawler Iii, E.E. Sustainable effectiveness and organization development. OD Pract. 2014, 46, 65-67.

12. Weigelt, C.; Miller, D.J. Implications of internal organization structure for firm boundaries. Strateg. Manag. J. 2013, 34, 1411-1434. [CrossRef]

13. Bailey, J.R.; Raelin, J.D. Organizations don't resist change, people do: Modeling individual reactions to organizational change through loss and terror management. Organ. Manag. J. Routledge 2015, 12, 125-138. [CrossRef]

14. Cummings, T.G.; Cummings, C. Appreciating organization development: A comparative essay on divergent perspectives. Hum. Resour. Dev. Q. 2014, 25, 141-154. [CrossRef] 
15. Sung, S.Y.; Choi, J.N. Do organizations spend wisely on employees? Effects of training and development investments on learning and innovation in organizations. J. Organ. Behav. 2014, 35, 393-412. [CrossRef] [PubMed]

16. Beer, M. Organization development at a crossroads. OD Pract. 2014, 46, 60-61.

17. Felkins, P.K.; Chakiris, B.J.; Chakiris, K.N. Change Management: A Model for Effective Organizational Performance; Productivity Press: Portland, OR, USA, 2001.

18. Gonçalves, M. Change Management: Concepts and Practice; ASME Press: New York, NY, USA, 2007.

19. Murthy, C.S.V. Change Management, 1st ed.; Himalaya Publishing House Pvt. Ltd.: Mumbai, India, 2007.

20. Merrell, P. Effective change management: The simple truth. Manag. Serv. 2012, 56, 20-23.

21. Bringselius, L.A. Employee objections to organizational change: A framework for addressing management responses. Organ. Dev. J. 2014, 32, 41-54.

22. Taborda, L.J. Enterprise Release Management: Agile Delivery of a Strategic Change Portfolio; Artech House: Boston, MA, USA, 2012.

23. Brock, W.B. Toward a Diagnostic-Dialogic Model of Organizational Change: Synthesizing Organizational Change with Accounting Metrics; ProQuest Information \& Learning: Ann Arbor, MI, USA, 2013.

24. Van de Ven, A.H.; Sun, K. Breakdowns in implementing models of organization change. Acad. Manag. Perspect. 2011, 25, 58-74. [CrossRef]

25. Laser, S.A. Diagnosis for organizational change: Methods and models. Pers. Psychol. 1995, 48, 409-412.

26. Weisbord, M.R. Organizational Diagnosis: A Workbook of Theory and Practice; Addison-Wesley Publishing Co.: Boston, MA, USA, 1978.

27. McIntyre, C. A Framework for Understanding iab Output and iab Management. Available online: http://www.acce-hq.org/images/uploads/IAB_Growth_Management_Model_Version_3.pdf (assessed on 3 January 2016).

28. Silvestri, L.; Gulati, R. From periphery to core: A process model for embracing sustainability. In Leading Sustainable Change: An organiZational Perspective, 1st ed.; Henderson, R., Gulati, R., Tushman, M., Eds.; Oxford University Press: Oxford, UK, 2015; pp. 81-110.

29. Li, F.; Wan, N.; Shi, B.; Liu, X.; Guo, Z. The vulnerability measure of tourism industry based on the perspective of "environment-structure" integration a case study of 31 provinces in mainland china. Geogr. Res. 2014, 33, 569-581.

30. Hong, T.; Jian, Z. Regional vulnerability evaluation index system of environmental emergencies in petrochemical industry. Adv. Mater. Res. 2014, 1073-1076, 400-404.

31. Chen, J.; Yang, X.; Wang, Z.; Zhang, L. Vulnerability and influence mechanisms of rural tourism socio-ecological systems: A household survey in China's qinling mountain area. Tour. Trib. 2015, 30, 64-75.

32. Anderson, D.; Ackerman-Anderson, L.S. Beyond Change Management: How to Achieve Breakthrough Results through Conscious Change Leadership, 2nd ed.; Pfeiffer: San Francisso, CA, USA, 2010.

33. McCalman, J.; Paton, R. Change Management: A Guide to Effective Implementation; Paul Chapman Publishing: London, UK, 1992.

34. Ha, H. Change Management for Sustainability; Business Expert Press: New York, NY, USA, 2014.

35. Giauque, D. Attitudes toward organizational change among public middle managers. Public Pers. Manag. 2015, 44, 70-98. [CrossRef]

36. Cook, S.; Macaulay, S.; Coldicott, H. Change Management Excellence: Using the Four Intelligences for Successful Organizational Change; Kogan Page: London, UK; Sterling, VA, USA, 2004.

37. Franklin, M. Agile Change Management: A Practical Framework for Successful Change Planning and Implementation; Kogan Page: London, UK, 2014.

38. Knuf, J. Benchmarking the lean enterprise: Organizational learning at work. J. Manag. Eng. 2000, 16, 58-71. [CrossRef]

39. Stegerean, R.; Gavrea, C.; Marin, A. The application of a diagnostic model: An empirical study. Stud. Univ. Babes Bolyai Negot. 2010, 3, 3-13.

40. Gavrea, C.; Stegerean, R.; Marin, A. Corporate board structure and organizational performance: Evidence from romanian firms. Stud. Univ. Babes Bolyai Negot. 2012, 57, 21-33.

41. Henderson, R., Gulati, R., Tushman, M., Eds.; Leading Sustainable Change: An Organizational Perspective, 1st ed.; Oxford University Press: Oxford, UK, 2015. 
42. Preziosi, R. Organizational Diagnosis Questionnaire. 22 October 2013; (EB/OL). Available online: http://g-rap.org/docs/ICB/Preziosi\%20-\%20Organ.\%20Diagnosis\%20Questionnaire\%20ODQ.pdf (assessed on 13 March 2016).

43. Lok, P.; Crawford, J. The application of a diagnostic model and surveys in organizational development. J. Manag. Psychol. 2000, 15, 108-125. [CrossRef]

44. Kontić, L. Applying the weisbord model as a diagnostic framework for organizational analysis. Industrija 2012, 40, 145-156.

45. Khan, M.M.S. Factors essential for longevity among dow jones index organisations: Qca analysis. J. Dev. Areas 2015, 49, 469-479. [CrossRef]

46. Ramnarayan, S.; Rao, T.V. Organization Development: Accelerating Learning and Transformation, 2nd ed.; SAGE/Response Business Books: New Delhi, India; Thousand Oaks, CA, USA, 2011.

47. Rahimi, H.; Siadat Sayyed, A.; Hoveida, R.; Shahin, A.; Nasrabadi Hasan, A.; Arbabisarjou, A. The analysis of organizational diagnosis on based six box model in universities. High. Educ. Stud. 2011, 1, 84-92.

48. Marketa, H. Organisational Structures for a Functional Campus Community; Lambert Academic Publishing: Saarbrücken, Germany, 2012.

49. Ramirez, G.A. Sustainable development: Paradoxes, misunderstandings and learning organizations. Learn. Organ. 2012, 19, 58-76.

50. Lee, A.H.I.; Chen, H.H.; Chen, S. Suitable organization forms for knowledge management to attain sustainable competitive advantage in the renewable energy industry. Energy 2015, 89, 1057-1064. [CrossRef]

51. Panagiotakopoulos, P.D.; Espinosa, A.; Walker, J. Sustainability management: Insights from the viable system model. J. Clean. Prod. 2015, 113, 792-806. [CrossRef]

52. DobrotĂ, D.; Iancu, C. Sustainable development of an industrial organization. Ann. Constantin Brancusi Univ. Targu Jiu Eng. Ser. 2015, 2, 164-173.

53. Newman, A.; Sheikh, A.Z. Organizational rewards and employee commitment: A chinese study. J. Manag. Psychol. 2012, 27, 71-89. [CrossRef]

54. Day, J.W.; Holladay, C.L.; Johnson, S.K.; Barron, L.G. Organizational rewards: Considering employee need in allocation. Pers. Rev. 2014, 43, 74-95.

55. Soares, M.M.; Jacobs, K.; Merlin, F.K.; do Valle Pereira, V.L.; Júnior, W.P. Sustainable development induction in organizations: A convergence analysis of iso standards management tools' parameters. Work 2012, 41, 2736-2743.

56. Ehnert, I., Harry, W., Zink, K.J., Eds.; Sustainability and Human Resource Management: Developing Sustainable Business Organizations; Springer: Berlin, Germany; New York, NY, USA, 2014.

57. Temponi, C. Scalable enterprise systems: Quality management issues. Int. J. Prod. Econ. 2006, 99, $222-235$. [CrossRef]

58. French, W. Organization development, objectives, assumptions and strategies. Calif. Manag. Rev. 1969, 12, 23-34. [CrossRef]

59. Kahnweiler, W.M. Organization development success and failure: A case analysis. Organ. Dev. J. 2010, 28, 19-28.

60. Pandey, S.; Sharma, R.R.K. Organization development interventions for prospectors: A theoretical framework and its empirical validation. Glob. Bus. Manag. Res. 2011, 3, 79-95.

61. Anderson, D.L. Organization development interventions and four targets of post-acquisition integration. OD Pract. 2012, 44, 19-24.

62. Pradhan, S.; Pradhan, R.K. An empirical investigation of relationship among transformational leadership, affective organizational commitment and contextual performance. Vision (09722629) 2015, 19, 227-235. [CrossRef]

63. Marlier, D.; Parker, C. Engaging Leadership: Three Agendas for Sustaining Achievement; Palgrave Macmillan: Basingstoke, UK; New York, NY, USA, 2009.

64. Hughes, M. The Leadership of Organizational Change, 1st ed.; Routledge: New York, NY, USA, 2016.

65. Farrell, M. Leadership reflections: Leadership development through service. J. Libr. Adm. 2014, 54, $308-317$. [CrossRef]

66. Aldana-Bobadilla, E.; Kuri-Morales, A. A clustering method based on the maximum entropy principle. Entropy 2015, 17, 151-180. [CrossRef] 
67. Bereziński, P.; Jasiul, B.; Szpyrka, M. An entropy-based network anomaly detection method. Entropy 2015, 17, 2367-2408. [CrossRef]

68. Benedetto, F.; Giunta, G.; Mastroeni, L. A maximum entropy method to assess the predictability of financial and commodity prices. Digit. Signal Process. 2015, 46, 19-31. [CrossRef]

69. Mei-rong, S.; Zhi-feng, Y. Set pair analysis for urban ecosystem health assessment based on emergy-vitality index. China Environ. Sci. 2009, 29, 892-896.

70. Creswell, J.W. Research Design: Qualitative, Quantitative, and Mixed Methods Approaches, 3rd ed.; Sage Publications: Thousand Oaks, CA, USA, 2009.

71. Davis, C. Spss Step by Step: Essentials for Social and Political Science; Policy Press: Bristol, UK, 2013.

72. Morgan, G.A. Spss for Introductory Statistics: Use and Interpretation, 3rd ed.; Lawrence Erlbaum: Mahwah, NJ, USA, 2007.

73. Brace, I. Questionnaire Design: How to Plan, Structure and Write Survey Material for Effective Market Research; Kogan Page: London, UK; Philadelphia, PA, USA, 2013.

74. Cunningham, J.B.; Aldrich, J.O. Using Spss: An Interactive Hands-On Approach; SAGE: Thousand Oaks, CA, USA, 2012.

75. Gliem, J.A.; Gliem, R.R. Calculating, interpreting, and reporting cronbach's alpha reliability coefficient for likert-type scales. In Midwest Research-to-Practice Conference in Adult, Continuing, and Community Education; Ohio State university: Columbus, OH, USA, 2003; pp. 82-88.

76. Jóhannsdóttir, L.; Ólafsson, S.; Davidsdottir, B. Leadership role and employee acceptance of change: Implementing environmental sustainability strategies within nordic insurance companies. J. Organ. Chang. Manag. 2015, 28, 72-96. [CrossRef]

77. Shatrevich, V. Industrial structures as competitive factor in organization development. Procedia Soc. Behav. Sci. 2014, 110, 871-878. [CrossRef]

78. Croft, C.; Currie, G.; Lockett, A. The impact of emotionally important social identities on the construction of a managerial leader identity: A challenge for nurses in the english national health service. Organ. Stud. 2015, 36, 113-131. [CrossRef]

79. Burns, J.; Shoup, J.R.; Simmons, D.C., Jr. Organizational Leadership: Foundations Practices for Christians; IVP Academic: Downers Grove, IL, USA, 2014.

80. Walumbwa, F.O.; Wu, C.; Orwa, B. Contingent reward transactional leadership, work attitudes, and organizational citizenship behavior: The role of procedural justice climate perceptions and strength. Leadersh. Q. 2008, 19, 251-265. [CrossRef]

81. Lawrence, P.R. Leading Change: The Challenge of Complexity, 1st ed.; Kogan Page: Philadelphia, PA, USA, 2015.

82. Mehta, M. Situational leadership and personal effectiveness: Managers in indian development organizations. Abhigyan 2012, 30, 23-34.

83. Warrick, D.D. The urgent need for skilled transformational leaders: Integrating transformational leadership and organization development. J. Leadersh. Account. Ethics 2011, 8, 11-26.

84. Datta, P. An applied organizational rewards distribution system. Manag. Decis. 2012, 50, 479-501. [CrossRef]

85. Bramante, J. The Enterprise of the Future: Turning Change into Opportunity; Board of Trustees of the Leland Stanford Junior University: Stanford, CA, USA, 2008.

86. Mabey, C. Leadership development in organizations: Multiple discourses and diverse practice. Int. J. Manag. Rev. 2013, 15, 359-380. [CrossRef]

87. Campbell, H. Managing Organizational Change: A Practical Toolkit for Leaders; Kogan Page: London, UK; Philadelphia, PA, USA, 2014.

88. Cheung-Judge, M.-Y.; Holbeche, L. Organization Development: A Practitioner's Guide for od and hr, 2nd ed.; Kogan Page: London, UK; Philadelphia, PA, USA, 2015.

(C) 2016 by the authors; licensee MDPI, Basel, Switzerland. This article is an open access article distributed under the terms and conditions of the Creative Commons by Attribution (CC-BY) license (http://creativecommons.org/licenses/by/4.0/). 